\title{
Wirtschaftsnot \\ und Selbsthilfe der deutschen Studentenschaft
}

von

\author{
Dr. Hans Gehrig
}

ord. Professor der Nationalökonomie in Dresden

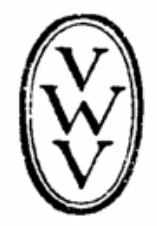

Berlin und Leipzig

Walter de Gruyter \& Co.

vormals G.J. Göschen'sche Verlagshandlung - J. Guttentag, Verlagsbuchbandlung Georg Reimer - Karl J. Trübner - Veit \& Comp. 
Druck von Walter de Gruyter \& Co., Berlin W. 10. 


\section{Gründern und Mitarbeitern \\ der}

\section{„Dresdner Hochschulwirtschaftsgenossenschaft“}

und der

\section{"Wirtschaftshilfe der Deutschen Studentenschaft"}

ist diese Schrift gewidmet.

Ihre Arbeit für die deutschen Hochschulen in dem Geiste des Arbeiterdichters: „Ein freier Deutscher kennt kein kaltes Müssen. Deutschland soll leben ... " möge allezeit Nachfolgeschaft finden! Dem zugleich diene diese von der Erfahrung, also auch von ihrem Wirken und Planen mitbeeinflußte Darstellung, die auch Kunde geben soll von ihrem Mühen, die wissenschaftliche Erziehung eines akademischen Nachwuchses uns möglich za halten. 
